\title{
Examining Mobile Payment User Adoption from the Perspective of Trust
}

\author{
Hong Yan and Zhonghua Yang \\ Wuhan University of Science and Technology, China \\ yanhong@wust.edu.cn,Yzh100@263.net
}

\begin{abstract}
This paper explored the critical factors influencing users' intention to adopt mobile payment from a trust perspective. The results are based on a survey sample of 193 participants. SmartPLS2.0 is employed in the data analysis. The findings indicate that perceived ease of use, perceived usefulness, structure assurance and ubiquity have significant effect on users' trust, which further affect user usage intention. Thus mobile service providers need to concern trust to facilitate user adoption and usage of mobile payment services.
\end{abstract}

Keywords: mobile payment; trust; structural assurance; user adoption

\section{Introduction}

With the advent of fourth generation $(4 \mathrm{G})$ mobile communication technologies, mobile commerce has acquired rapid development. According to a report issued by China Internet Network Information Center(CNNIC), the number of mobile Internet users in China exceeded 500 million, accounting for $81 \%$ of its Internet population( 618 million) by 2013 [1]. Faced with this opportunity, mobile service providers have released a variety of services, which can be classified into four categories: communication, information, entertainment and transaction [2]. The CNNIC report indicates that the entertainment applications such as mobile music, video and games have been very popular among users [1]. In comparison, mobile payment as a transaction application has only been adopted by a minority of users. Nevertheless, mobile payment as an emerging service has great potential.

Mobile payment means that users adopt mobile terminals such as cell phones to access payment services including account inquiry, transference and bill payment. With the help of mobile terminals and networks, mobile payment has freed users from the temporal and spatial limitations, and enabled them to conduct payment at anytime from anywhere. Almost all Banks provides the mobile payment services to users. They all expect users to widely adopt and use mobile payment. Then they can take advantage in the fierce market competition. The CNNIC report indicates that mobile payment is still in its early stage of development (15.2\% of acceptance rate).

Considering the low adoption rate of mobile payment, it is necessary to identify the factors affecting mobile payment user adoption. On one hand, due to the virtuality and lack of control, mobile payment involves great uncertainty and risk. Especially, compared to wired networks, mobile networks may be more vulnerable to hacker attack and information interception. This leads to users' concern about mobile payment security. They doubt whether mobile payment can effectively protect their account and payment from potential problems. If they cannot engender enough trust in mobile payment, they will not adopt and use it. On the other hand, compared to desktop computers, mobile terminals such as cell phones have some constraints such as small screens, low resolution and inconvenient input, which make it 
difficult for mobile users to search for relevant information. In addition, users always expect to acquire ubiquitous and reliable mobile payment services.

The technology acceptance model (TAM) is a well-recognized model used to explain information system adoption behavior [3]. According to the TAM, adoption behavior is determined by the intention to utilize a particular system, which is, in turn, determined by the perceived usefulness and the perceived ease of use of the system. One major benefit of using the TAM is that it provides a framework by which the effect of external variables on system usage can be assessed.

A number of studies have focused on the adoption factors of mobile payment. These studies have been based primarily on the TAM, with additional constructs adapted for the study of mobile payment such as security, cost, mobility, use situation, expressiveness, convenience, speed of transaction, social reference groups, facilitating condition, the attractiveness of alternatives, privacy, system quality, and technology anxiety [4-10]. But few paper examine mobile payment user adoption from the trust perspective. This paper integrated both TAM and trust theory to examine mobile payment user adoption. We included perceived ease of use, perceived usefulness, structural assurance and ubiquity into the model as the determinants. Trust act as a mediator between these four determinants and usage intention.

The rest of this paper is organized as follows. The research theoretical background and research hypotheses are presented in Section 2. Next, Section 3 reports instrument development and data collection. The data analysis and results are reported in section 4. Finally, section 5 follows with the summary, contributions, implications, and limitations of the study.

\section{Theory Background and Research Hypotheses}

In this section, the theoretical background of our study is developed with the literature review of technology acceptance theories, trust, online and mobile payment adoption. Based on these theories, we developed the research hypotheses.

\subsection{Technology Acceptance Theories}

A number of research models have been introduced to explain computer-usage behavior. Fishbein and Ajzen's Theory of Reasoned Action (TRA) [11], which depicts user behavior from social psychology's point, is the theoretical basis of Theory of Planned Behavior (TPB) [12], Technology Acceptance Model and Unified Theory of Acceptance and Use of Technology (UTAUT) [13]. TRA is very general in nature and attempts to explain almost any human behavior. According to TRA, a person's performance of a specified behavior is determined by his or her behavioral intention (BI) to perform the behavior, and $\mathrm{BI}$ is jointly determined by the person's attitude and subjective norm concerning the behavior in question. TAM is one of the first and the most influential research models to explain users' IT adoption behavior. The TAM has been recognized as a useful model of technology acceptance behaviors in a variety of IT contexts, and is currently widely applied among researchers of information systems in general. The fundamental rationale of the TAM is that IT users act rationally when they decide to use an IT. In the process of users' intention to use new IT, two belief variables - perceived usefulness and perceived ease of use of the system - are the most salient factors in users' intention. Perceived usefulness is defined as the degree to which a person perceives that adopting the system will boost his/her job performance. Perceived ease of use is defined as the degree to which a person believes that adopting the system will be free of effort. Perceived usefulness has an immediate effect on adoption intention, whereas 
perceived ease of use has both an immediate effect and an indirect effect on adoption intention via perceived usefulness. In TAM2 (Venkatesh \& Davis, 2000) [14], an extended TAM, social and organizational variables such as subjective norm, image, job relevance, output quality, and result demonstrability are included in the model. All these factors are shown to have direct impact on perceived usefulness. In addition, the study shows that subjective norm not only influences perceived usefulness, but also has impact on user intention.

\subsection{Trust}

In commercial transactions, especially in the online or mobile context, trust plays an important role due to the high degree of uncertainties and risks involved. Due to its significant role, trust has received considerable attention in information systems research. The factors identified to affect online trust include website-based, user-based, company-based determinants [15]. Similar to online transaction, mobile transactions also involve great risk. Thus it is critical to building mobile user trust [16-17]. Compared to the abundant research on online trust, mobile trust has just begun to receive attention from researchers. Lin and Wang [18] revealed that trust has significant effects on mobile user satisfaction and loyalty. Li and Yeh [19] argued that design aesthetics affect mobile trust through ease of use, usefulness and customization. Vance et al. [20] examined the effect of system quality including visual appeal and navigational structure on mobile user trust.

\subsection{Online and Mobile Payment Adoption}

Online payment represents a type of electronic banking and its adoption has received considerable attention from researchers. And most research has been conducted from the perspective of the technology acceptance model. Laforet and $\mathrm{Li}$ [21] compared the factors affecting Chinese users' adoption of online and mobile banking. The results indicated that security is the main factor affecting online banking adoption, whereas lack of awareness and understanding of benefits is the main factor affecting mobile banking adoption. Lee, T. [22] found that offline banking trust has significant effects on online banking users' flow, structural assurance, satisfaction and perceived extent of use. Lee et al. [23] examined user switch from offline banking to online banking. Their results indicated that perceived usefulness, perceived ease of use, offline trust, offline loyalty and switch cost affect user attitude towards switching. Al-Somali et al. [24] found that perceived usefulness, perceived ease of use and trust affect online payment acceptance in Saudi Arabia. Liao and Cheung [25] suggested that usefulness, ease of use, reliability, security, responsiveness and continuous improvement affect user satisfaction with online payment. Yiu et al. [26] noted that perceived usefulness, perceived ease of use, perceived risk and personal innovativeness affect online payment adoption in Hong Kong.

As an emerging service, mobile payment adoption has also gained attention from researchers. Luo et al. [4] integrated trust theory and the unified theory of acceptance and use of technology (UTAUT) to examine mobile payment user behavior. Their results show that trust has effects on perceived risk and performance expectancy, further determining behavioral intention. Kim et al. [5] reported that structural assurance, relative benefits and personal propensity to trust affect initial trust in mobile payment. Lin [27] integrated innovation diffusion theory (IDT) and trust theory to examine mobile payment adoption. Their results indicated that relative advantage and perceived competence have strong effects on user attitude towards mobile banking. Shen et al. [28] examined mobile banking adoption from a benefit-cost perspective. They suggested that the key benefit of mobile payment is convenience, whereas the key cost is security. 
Comparing above research on online and mobile payment adoption, we can find that trust has been found to be a significant determinant of user behavior. Nevertheless, there may exist some differences between the factors affecting both online and mobile payment adoption. For example, compared to online banking, the main advantage of mobile payment is ubiquity, which enables users to access payment services at anytime from anywhere. In addition, mobile payment needs strong structural assurance as it involves great uncertainty and risk due to possible information interception and hacker attack associated with mobile networks. Thus it is necessary to take these unique characteristics such as ubiquity and structural assurance into consideration when examining mobile payment user adoption. Our research model tries to capture the effects of these factors on mobile payment user behavior.

\subsection{Research Model and Hypotheses}

Figure 1 presents the research model. Structural assurance, ubiquity, perceived ease of use and perceived usefulness are proposed to affect trust. In addition, further affect user usage intention. Perceived ease of use is a main component of TAM [3]. It reflects the difficulty of using mobile payment. Due to the constraints of mobile terminals such as small screens and inconvenient input, it may be difficult for users to operate mobile payment if service providers cannot present a good interface to users. An easy-to-use mobile payment with welldesigned interfaces and powerful navigation will reflect service providers' ability and benevolence, thus affecting user trust. In addition, an easy-to-use mobile payment system will also reduce users' effort spent on learning to use mobile payment and increase their feelings of perceived control. This helps focus users' attention on the main activity and improve their experience. The effect of perceived ease of use on trust has been validated in previous research $[3,20]$. Thus, we hypothesize:

H1: Perceived ease of use positively affects user trust.

$\mathrm{H} 2$ : Perceived usefulness positively affects user trust.

H3: Perceived ease of use positively affects perceived usefulness.

Structural assurance as an institution-based trust mechanism can effectively build users' trust in and decrease their perceived risk with online transactions [30]. Structural assurance means that there exist adequate technological and legal structures to ensure payment security. Compared to online payment, mobile payment built on wireless networks may be more vulnerable to hacker attack and information interception. In addition, viruses and Trojan horses may exist in mobile terminals. These problems will affect the account and money security. Thus, if there exist enough structural assurances such as certification and regulations to ensure payment security, users can build their trust in mobile payment because they may transfer their trust in these third-party mechanisms to mobile payment. Thus, we hypothesize:

H4: Structural assurance positively affects user trust.

Ubiquity means that with the help of mobile terminals and networks, users can access mobile payment at anytime from anywhere. Ubiquity is a main advantage of mobile payment compared to traditional and online payment. It frees users from the spatial and temporal limitations and enables them to conduct ubiquitous payment. Nevertheless, presenting ubiquitous services to users is not easy for service providers. They need to spend continuous effort and resources on ensuring ubiquitous mobile payment services. Thus ubiquity will act as a trustworthiness signal. If users cannot acquire reliable and ubiquitous services, they may decrease their evaluations on service providers' ability and integrity. Lee [39] also pointed out the positive effect of ubiquitous connection on mobile trust. Thus, we hypothesize:

H5: Ubiquity positively affects user trust.

Trust reflects a willingness to be in vulnerability based on the positive expectations towards another party's future behavior. Trust often includes three dimensions: ability, 
integrity and benevolence [27]. Ability reflects that service providers have the skills and knowledge necessary to fulfill their tasks. Integrity reflects that service providers keep their promises and do not deceive users. Benevolence reflects that service providers keep users' interests in mind and will not just care their own benefits. Trust will affect usage intention. Trust helps alleviate the uncertainty and risk associated with using mobile payment, and will promote user behavior. According to the theory of reasoned action (TRA), trust as user belief will affect behavioral intention, which in turn affects actual behavior [11]. Thus, we hypothesize:

H6: Trust positively affects usage intention.

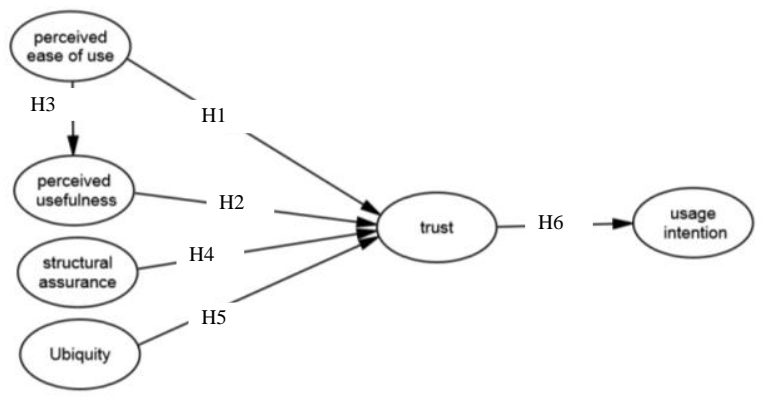

Figure 1. The Research Model

\section{Method and Data Collection}

The research model includes six factors. Each factor was measured with multiple items. All items were adapted from extant literature to improve content validity. The items measuring perceived ease of use and perceived usefulness were both adapted from Agarwal and Karahanna [37]; the items measuring structural assurance were adapted from McKnight et al. [38]; the items measuring ubiquity, trust and usage intention were all adapted from Lee [39]. Both researchers had knowledge on e-business and expertise on English-Chinese translation. There were no significant discrepancies between the original English items and the back-translated items. When the instrument was developed, it was tested among ten users that had mobile payments experience. According to their comments, we revised some items to improve the clarity and understandability. All items were measured with a seven-Likert scale ranging from strongly disagree (1) to strongly agree (7).

Data were collected at a university located in a central China city. We feel that selecting students as our subjects is appropriate as they represent the largest group of mobile internet users now. They are also potential mobile payment users, which fit our research context. In order to obtain a representative sample, we distributed the questionnaires among students with amateur degree, bachelor degree and graduate degree, respectively. Researchers first inquired whether the students had online payments usage experience. Then we invited those with previous experience to participate in our survey. After that, users were asked to fill the questionnaire based on their experience. We scrutinized all responses and dropped those with too many missing values, which may affect estimation results in data analysis. As a result, we obtained 193 valid responses. Among them, 56.5\% were male and $43.5 \%$ were female. A majority of them (95\%) had conducted electronic trading for more than one year. Table I shows the demographic information of the sample. 
Table 1. The Demographic Information of The Sample

\begin{tabular}{|c|c|c|c|}
\hline & option & count & percentage \\
\hline \multirow[t]{2}{*}{ Gender } & Male & 109 & 56.5 \\
\hline & female & 84 & 43.5 \\
\hline \multirow[t]{3}{*}{ Age(years old) } & $<20$ & 55 & 28.5 \\
\hline & $20-25$ & 92 & 47.7 \\
\hline & $>25$ & 46 & 23.8 \\
\hline \multirow[t]{3}{*}{ Education } & Associate degree & 32 & 16.6 \\
\hline & Bachelor degree & 98 & 50.8 \\
\hline & Master degree and higher & 63 & 32.6 \\
\hline \multirow{3}{*}{$\begin{array}{l}\text { Electronic trading } \\
\text { experience }\end{array}$} & $<1$ year & 9 & 4.66 \\
\hline & 1-3years & 25 & 12.9 \\
\hline & $>3$ years & 159 & 82.4 \\
\hline
\end{tabular}

\section{Data Analysis and Results}

We employed SmartPLS2.0 to verify our measurement and theoretical model, since the partial least squares (PLS) algorithm is a components-based structural equation modeling technique that has gained acceptance among IS researchers [32-33]. As an alternative to the more widely known covariance fitting approach (exemplified by software such as LISREL, EQS, and AMOS), the component-based PLS is better suited for explaining complex relationships as it avoids two serious problems: inadmissible solutions and factor indeterminacy [34]. Being a components-based structural equation modeling technique, PLS "is similar to regression, but simultaneously models the structural paths (i.e., theoretical relationships among latent variables) and measurement paths (i.e., relationships between a latent variable and its indicators), allowing each indicator to vary in how much it contributes to the composite score of the latent variable," thus being "preferable to other techniques" [35].

Before testing the hypothesized relationships, we first assessed measurement validity, including content validity, convergent validity, and discriminant validity. With regard to content validity, since all constructs and items are based on the previous literature, subject to minor improvements in wordings after the pilot survey, we thus believe each of them is accurately expressed and has a clear meaning.

The whole measurement model comprises six constructs. After running the model, we obtained results that support the convergent validity and discriminant validity. Factorial validity such as item loadings and cross-loadings can also be used to help assess convergent validity and discriminant validity [36].

Table II shows the Standardized item loading (SIL), average variance extracted (AVE), composite reliability (CR), and Cronbach's Alpha of each construct. We can see that all the values of CR are greater than 0.836 and all the values of Cronbach's Alpha are greater than 0.712 , which suggests a good degree of reliability and convergent validity of all the reflective constructs [36].

Table 2. Standardized Item Loading, Ave, Cr And Alpha Values

\begin{tabular}{llllll}
\hline factor & Item & SIL & AVE & CR & Alpha value \\
\hline Perceived Ease of use & EOU1 & 0.757 & & & \\
& EOU2 & 0.855 & 0.662 & 0.855 & 0.745 \\
& EOU3 & 0.826 & & & \\
\hline Perceived Usefulness & PU1 & 0.782 & & & \\
& PU2 & 0.821 & 0.635 & 0.839 & 0.712 \\
& PU3 & 0.786 & & & \\
\hline Structural Assurance & SA1 & 0.871 & & & \\
& SA2 & 0.809 & 0.652 & 0.848 & \\
& SA3 & 0.737 & & & \\
\hline
\end{tabular}




\begin{tabular}{llllll}
\hline UB & UB1 & 0.764 & & \\
& UB2 & 0.796 & 0.629 & 0.836 & 0.754 \\
& UB3 & 0.819 & & & \\
\hline Trust & TRUST1 & 0.845 & & & \\
& TRUST2 & 0.877 & 0.714 & 0.882 & 0.8 \\
& TRUST3 & 0.812 & & & \\
\hline Usage Intention & UI1 & 0.816 & & & \multirow{2}{*}{0.886} \\
& UI2 & 0.840 & 0.697 & 0.902 & \\
& UI3 & 0.823 & & & \\
& UI4 & 0.860 & & & \\
\hline
\end{tabular}

Table III shows the correlations between constructs and square roots of AVE. We can see that the square root of each construct's AVE is larger than its correlations with other constructs, suggesting sufficient discriminant validity [36].

Table 3. The Square Root of Ave (Shown As Bold At Diagonal) and Factor Correlation Coefficients

\begin{tabular}{|c|c|c|c|c|c|c|}
\hline & EOU & $\mathrm{PU}$ & SA & UB & TRUST & UI \\
\hline EOU & 0.813 & & & & & \\
\hline $\mathrm{PU}$ & 0.509 & 0.797 & & & & \\
\hline SA & 0.479 & 0.467 & 0.807 & & & \\
\hline UB & 0.458 & 0.512 & 0.51 & 0.793 & & \\
\hline TRUST & 0.56 & 0.585 & 0.622 & 0.538 & 0.845 & \\
\hline UI & 0.525 & 0.545 & 0.557 & 0.515 & 0.541 & 0.842 \\
\hline
\end{tabular}

Table IV shows the loadings and cross-loadings where all items load much higher on their specified constructs than on other constructs, further suggesting sufficient discriminant and convergent validity for all constructs used in this study.

It is suggested that using single-source, self-reported data may have the potential for common method bias, while obtaining data from different sources can help reduce common method variance (CMV) [41]. Harman's single-factor test is arguably the most extensively applied approach for assessing CMV. Harman's single-factor test was performed with the complete data set by conducting a principal components analysis (PCA) in SPSS. The factor solution resulted in six factors with eigenvalues greater than 1.0, accounting for $83.29 \%$ of variance. At the same time, the first factor accounted for $18.69 \%$ of the variance, indicating that this factor does not account for the majority of the variance [41].

Table 4. The Loadings and Cross Loadings

\begin{tabular}{lllllll}
\hline & EOU & PU & SA & UB & TRUST & UI \\
\hline EOU1 & $\mathbf{0 . 7 5 7}$ & 0.409 & 0.468 & 0.322 & 0.329 & 0.567 \\
EOU2 & $\mathbf{0 . 8 5 5}$ & 0.417 & 0.477 & 0.387 & 0.278 & 0.516 \\
EOU3 & $\mathbf{0 . 8 2 6}$ & 0.435 & 0.458 & 0.377 & 0.341 & 0.543 \\
PU1 & 0.583 & $\mathbf{0 . 7 8 2}$ & 0.602 & 0.641 & 0.509 & 0.421 \\
PU2 & 0.525 & $\mathbf{0 . 8 2 1}$ & 0.578 & 0.403 & 0.499 & 0.413 \\
PU3 & 0.560 & $\mathbf{0 . 7 8 6}$ & 0.530 & 0.413 & 0.483 & 0.454 \\
SA1 & 0.458 & 0.428 & $\mathbf{0 . 8 7 1}$ & 0.563 & 0.338 & 0.389 \\
SA2 & 0.490 & 0.433 & $\mathbf{0 . 8 0 9}$ & 0.529 & 0.359 & 0.312 \\
\hline
\end{tabular}




\begin{tabular}{lllllll}
\hline SA3 & 0.472 & 0.415 & $\mathbf{0 . 7 3 7}$ & 0.504 & 0.303 & 0.337 \\
UB1 & 0.623 & 0.508 & 0.440 & $\mathbf{0 . 7 6 4}$ & 0.424 & 0.424 \\
UB2 & 0.598 & 0.381 & 0.401 & $\mathbf{0 . 7 9 6}$ & 0.461 & 0.480 \\
UB3 & 0.643 & 0.466 & 0.412 & $\mathbf{0 . 8 1 9}$ & 0.450 & 0.435 \\
TRUST1 & 0.432 & 0.238 & 0.486 & 0.369 & $\mathbf{0 . 8 4 5}$ & 0.502 \\
TRUST2 & 0.467 & 0.291 & 0.504 & 0.449 & $\mathbf{0 . 8 7 7}$ & 0.551 \\
TRUST3 & 0.455 & 0.385 & 0.478 & 0.470 & $\mathbf{0 . 8 1 2}$ & 0.491 \\
UI1 & 0.286 & 0.372 & 0.569 & 0.487 & 0.381 & $\mathbf{0 . 8 1 6}$ \\
UI2 & 0.344 & 0.405 & 0.389 & 0.451 & 0.345 & $\mathbf{0 . 8 4 0}$ \\
UI3 & 0.439 & 0.488 & 0.429 & 0.399 & 0.291 & $\mathbf{0 . 8 2 3}$ \\
UI4 & 0.378 & 0.471 & 0.482 & 0.428 & 0.374 & $\mathbf{0 . 8 6 0}$ \\
\hline
\end{tabular}

Furthermore, following Podsakoff et al. [41] and Liang et al. [42], we included in the PLS model a common method factor whose indicators included all the principal constructs' indicators. "For each single-indicator construct, we examined the coefficients of its two incoming paths from its substantive construct and the method factor" [42]. As shown in Table 5, for all the 19 items, most method path coefficients are not significant. Meanwhile, the path coefficients of substantive constructs are substantially greater than their method path coefficients, thus explaining substantially greater variance of items than method. So, we contend that common method bias is not a concern in this study.

The bootstrap is described as "a computer-based method for assigning measures of accuracy to statistical estimates" and the usual measure of accuracy for statistical quantities is the standard error [43]. In traditional methods, "a standard error is usually estimated from equations that are derived from a series of assumptions and mathematical operations" [43]. For the bootstrap method, it "involves having a computer program generate a series of data sets (bootstrap samples) that are designed to resemble the ones that would be observed if the estimation study were repeated many times. Each bootstrap data set is obtained by sampling (with replacement) from the original data" [43]. Thus bootstrap procedures can draw repeated random samples from the data set and use these samples to estimate standard errors and calculate $t$ statistics for inferential purposes [43].

Table 5. Path Coefficients and Their Significance

\begin{tabular}{lllll}
\hline Hypothesis & Path & Coefficient & $T$ values & Supported or not \\
\hline H1 & EOU TRUST & $0.23^{* *}$ & 2.93 & Yes \\
H2 & PU TRUST & $0.41^{* * *}$ & 5.22 & Yes \\
H3 & EOU PU & $0.20^{* *}$ & 2.34 & Yes \\
H4 & SA TRUST & $0.42^{* * *}$ & 4.98 & Yes \\
H5 & UB TRUST & $0.28^{* *}$ & 3.52 & Yes \\
H6 & TRUST UI & $0.37^{* * *}$ & 4.58 & Yes \\
\hline
\end{tabular}

The structural model with results is presented in Figure 2. Test of significance were performed using the bootstrap resampling procedure with 1,000 samples, following the recommendation that the sample size should be at least 500[43], so as to obtain the stable $t$ values of the estimates. From Figure 2, we can see that all the hypotheses are supported. The 
results indicate that structural assurance, ubiquity, perceived ease of use and perceived usefulness affect trust. Trust has a significant effect on usage intention.

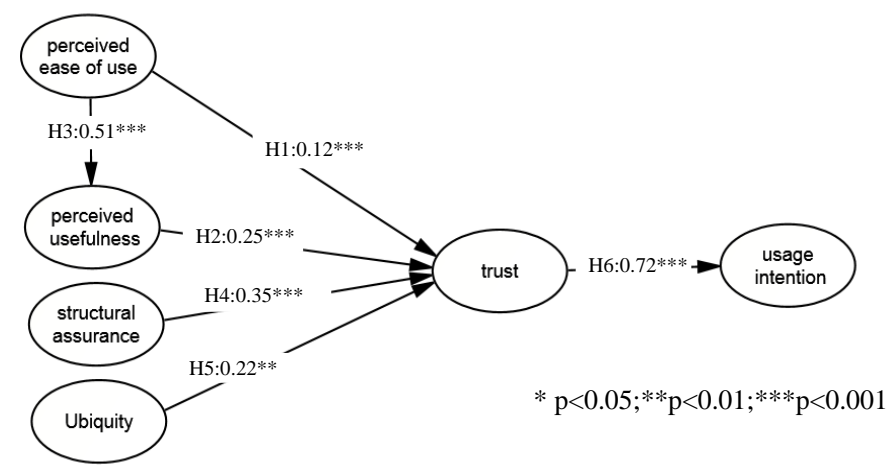

Figure 2. The Research Model with Result

\section{Discussion}

The aim of this study is to examine users' acceptance of mobile payment from a trust perspective. From Figure 2, we can see that all hypotheses are supported. The results indicate that structural assurance, ubiquity, perceived ease of use and perceived usefulness affect trust. Trust has a significant effect on usage intention. Among the factors affecting trust, structural assurance has the largest effect ( $c=0.35$ ). This is consistent with Kim et al. [5], which reports that structural assurance has a strong effect on initial trust in mobile payment. Thus mobile payment service providers need to adopt advanced encryption and third-party certification to increase user trust. They can use secure socket layer (SSL) encryption and digital certificates to ensure payment security. They can also display trust-seals such as VeriSign to demonstrate that they have been verified by the authoritative organizations. Besides structural assurance, ubiquity, perceived ease of use and perceived usefulness have significant effects on trust. Thus whether mobile service providers can provide ubiquitous and usefulness services will affect users' evaluations on their ability and benevolence. It is worth noting that to some extent, ubiquity also means vulnerability as ubiquity is built on wireless network, which is vulnerable to information interception and hacker attack. In this research, we mainly measured ubiquity with items reflecting service providers' ability to provide ubiquitous mobile payment services to users. If users feel that service providers have this ability, they may build trust. We also found that trust has a significant effect on usage intention. If users do not trust mobile service providers, they will not expect positive experience associated with using mobile payment. The significant effect of trust on usage intention is consistent with prior research findings $[3,5]$. This also highlights the necessity to build users' trust to facilitate their adoption and usage of mobile payment.

\section{Implications and Limitations}

This study has both theoretical and practical contributions. From a theoretical standpoint, while TAM has been extensively applied in prior research on user adoption in the virtual marketplace, prior research mostly focuses on factors that might be effective in predicting behavioral intention in a relative single channel.

From a theoretical perspective, this research examined mobile payment user adoption from the perspectives of trust. As noted earlier, extant research such as Kim et al. [5] has paid attention to the effect of trust on mobile payment user behavior due to the high uncertainty 
and perceived risk. However, the effect of structure assurance and ubiquity has seldom been examined. The results support this argument and indicate that mobile payment user behavior is affected by trust. This advances our understanding of mobile payment user behavior. This research also extends extant studies on online payment adoption, which mainly use TAM as the theoretical base and reveal the significant effect of perceived usefulness and perceived ease of use on user behavior. Future research can combine more important factors to examine mobile payment user behavior.

From a managerial perspective, our results imply that service providers need to concern both trust to facilitate mobile payment user behavior. On one hand, they should attach great importance to building user trust. Due to the uncertainty and potential risk associated with using mobile payment, building users' trust is critical to their adoption and usage behavior. We found that structural assurance is the main factor affecting trust. Thus mobile service providers need to employ technological and legal structures to engender user trust in mobile payment. We found that perceived ease of use, perceived usefulness and ubiquity are the three main factors affecting trust. This indicates that mobile service providers need to present usefulness and ubiquitous services to users.

This research has the following limitations. First, we collected data in China, where mobile commerce is developing rapidly but still in its infancy. Thus the research results need to be generalized to other countries that had developed mobile commerce. Second, besides the four factors including perceived ease of use, perceived usefulness, structural assurance and ubiquity there may exist other factors affecting user behavior, such as network effect. When more peers adopt mobile payment, individual user may also adopt it to facilitate the payment in his social circle. Future research can explore the possible effect of network externality on mobile payment user behavior. Third we mainly conducted a cross-sectional study. However, user behavior is dynamic. Thus a longitudinal research may provide more insights on user behavior development.

\section{Acknowledgements}

This research was supported by Humanity and Social Science Youth Foundation of Ministry of Education under Grant No.12YJC630266, by the Special Task Projtect of Humanities and Social Sciences Research-Engineering Science and Technoloty Talent Training Research under Grant No.13JDGC009 from the state Education Misnistry, by Humanities and Social Science Foundation of Hubei Provincial Department of Education under Grant 14G116, by Natural Science Foundation of HuBei Provice of China under Grant No.2014CFB804.

\section{References}

[1] CNNIC (2013), 32th statistical survey report on the Internet development in China, China Internet Network Information Center.

[2] T. Zhou, "Examining mobile banking user adoption from the perspectives of trust and flow experience", Information Technology and Management, vol. 13, no. 1, (2012), pp. 27-37.

[3] F. D. Davis, "Perceived usefulness, perceived ease of use, and user acceptance of information technology", MIS quarterly, (1989), pp. 319-340.

[4] X. Luo, H. Li, J. Zhang and J. P. Shim, "Examining multi-dimensional trust and multi-faceted risk in initial acceptance of emerging technologies: An empirical study of mobile banking services", Decision Support Systems, vol. 49, no. 2, (2010), pp. 222-234.

[5] G. Kim, B. Shin and H. G. Lee, "Understanding dynamics between initial trust and usage intentions of mobile banking”, Information Systems Journal, vol. 19, no. 3, (2009), pp. 283-311. 
[6] A. Y. L. Chong, F. T. S. Chan and K. B. Ooi, "Predicting consumer decisions to adopt mobile commerce: Cross country empirical examination between China and Malaysia [J]", Decision Support Systems, vol. 53, no. 1, (2012), pp. 34-43.

[7] E. Slade, M. Williams and Y. Dwivdei, "Extending UTAUT2 To Explore Consumer Adoption Of Mobile Payments [J]", (2013).

[8] E. L. Slade, M. D. Williams and Y. K. Dwivedi, "Developing a theoretically grounded model to explore adoption of mobile payments [J]", NASCENT CONNECTIONS 2013, (2013), p. 1.

[9] F. J. Liébana-Cabanillas, J. Sánchez-Fernández and F. Muñoz-Leiva, "Role of gender on acceptance of mobile payment [J]", Industrial Management \& Data Systems, vol. 114, no. 2, (2014), pp. 220-240.

[10] T. Zhou, "An empirical examination of initial trust in mobile payment [J]", Wireless Personal Communications, (2014), pp. 1-13.

[11] M. Fishbein and I. Ajzen, "Belief, attitude, intention and behavior: An introduction to theory and research", (1975).

[12] I. Ajzen, "The theory of planned behavior [J]", Organizational behavior and human decision processes, vol. 50, no. 2, (1991), pp. 179-211.

[13] V. Venkatesh, M. G. Morris and G. B. Davis, "User acceptance of information technology: Toward a unified view [J]", MIS quarterly, (2003), pp. 425-478.

[14] V. Venkatesh, F. D. Davis, "A theoretical extension of the technology acceptance model: four longitudinal field studies [J]", Management science, vol. 46, no. 2, (2000), pp. 186-204.

[15] D. H. McKnight, V. Choudhury and C. Kacmar, "Developing and validating trust measures for e-commerce: an integrative typology", Information systems research, vol. 13, no. 3, (2002), pp. 334-359.

[16] A. Beldad, M. De Jong and M. Steehouder, "How shall I trust the faceless and the intangible? A literature review on the antecedents of online trust", Computers in Human Behavior, vol. 26, no. 5, (2010), pp. 857869.

[17] K. Varnali and A. Toker, "Mobile marketing research: The-state-of-the-art", International Journal of Information Management, vol. 30, no. 2, (2010), pp. 144-151.

[18] H. H. Lin and Y. S. Wang, "An examination of the determinants of customer loyalty in mobile commerce contexts", Information \& management, vol. 43, no. 3, (2006), pp. 271-282.

[19] Y. M. Li and Y. S. Yeh, 'Increasing trust in mobile commerce through design aesthetics", Computers in Human Behavior, vol. 26, no. 4, (2010), pp. 673-684.

[20] A. Vance, C. Elie-Dit-Cosaque and D. W. Straub, "Examining trust in information technology artifacts: the effects of system quality and culture", Journal of Management Information Systems, vol. 24, no. 4, (2008), pp. 73-100.

[21] S. Laforet and X. Li, "Consumers' attitudes towards online and mobile banking in China”, International Journal of Bank Marketing, vol. 23, no. 5, (2005), pp. 362-380.

[22] T. Lee, "The impact of perceptions of interactivity on customer trust and transaction intentions in mobile commerce", Journal of Electronic Commerce Research, vol. 6, no. 3, (2005), pp. 165-180.

[23] K. C. Lee, I. Kang and D. H. McKnight, "Transfer from offline trust to key online perceptions: an empirical study", Engineering Management, IEEE Transactions on, vol. 54, no. 4, (2007), pp. 729-741

[24] S. A. Al-Somali, R. Gholami and B. Clegg, "An investigation into the acceptance of online banking in Saudi Arabia”, Technovation, vol. 29, no. 2, (2009), pp. 130-141.

[25] Z. Liao and M. T. Cheung, "Measuring consumer satisfaction in internet banking: a core framework", Communications of the ACM, vol. 51, no. 4, (2008), pp. 47-51.

[26] C. S. Yiu, K. Grant and D. Edgar, "Factors affecting the adoption of Internet Banking in Hong Kongimplications for the banking sector", International Journal of Information Management, vol. 27, no. 5, (2007), pp. 336-351.

[27] H. F. Lin, "An empirical investigation of mobile banking adoption: the effect of innovation attributes and knowledge-based trust", International Journal of Information Management, vol. 31, no. 3, (2011), pp. 252260.

[28] Y. C. Shen, C. Y. Huang, C. H. Chu and C. T. Hsu, "A benefit-cost perspective of the consumer adoption of the mobile banking system”, Behaviour \& Information Technology, vol. 29, no. 5, (2010), pp. 497-511.

[29] P. A. Pavlou and D. Gefen, "Building effective online marketplaces with institution-based trust", Information Systems Research, vol. 15, no. 1, (2004), pp. 37-59.

[30] J. Benamati, M. A. Fuller, M. A. Serva and J. Baroudi, "Clarifying the integration of trust and TAM in ecommerce environments: implications for systems design and management", Engineering Management, IEEE Transactions on, vol. 57, no. 3, (2010), pp. 380-393.

[31] P. A. Pavlou and D. Gefen, "Building effective online marketplaces with institution-based trust", Information Systems Research, vol. 15, no. 1, (2004), pp. 37-59.

[32] W. He and K. K. Wei, "What drives continued knowledge sharing? An investigation of knowledgecontribution and-seeking beliefs”, Decision Support Systems, vol. 46, no. 4, (2009), pp. 826-838. 
[33] Y. Yan and R. M. Davison, "Exploring behavioral transfer from knowledge seeking to knowledge contributing: The mediating role of intrinsic motivation", Journal of the American Society for Information Science and Technology, vol. 64, no. 4, (2013), pp. 1144-1157

[34] C. Fornell and F. L. Bookstein, "Two structural equation models: LISREL and PLS applied to consumer exit-voice theory", Journal of Marketing research, (1982), pp. 440-452.

[35] W. W. Chin, B. L. Marcolin and P. R. Newsted, "A partial least squares latent variable modeling approach for measuring interaction effects: Results from a Monte Carlo simulation study and an electronic-mail emotion/adoption study", Information systems research, vol. 14, no. 2, (2003), pp. 189-217.

[36] D. Straub, M. C. Boudreau and D. Gefen, "Validation guidelines for IS positivist research", Communications of the Association for Information Systems, vol. 13, no. 24, (2004), pp. 380-427.

[37] R. Agarwal and E. Karahanna, "Time flies when you're having fun: Cognitive absorption and beliefs about information technology usage [J]”, MIS quarterly, (2000), pp. 665-694.

[38] D. H. McKnight, V. Choudhury and C. Kacmar, "Developing and validating trust measures for e-commerce: an integrative typology [J]", Information systems research, vol. 13, no. 3, (2002), pp. 334-359.

[39] T. Lee, "The impact of perceptions of interactivity on customer trust and transaction intentions in mobile commerce [J]", Journal of Electronic Commerce Research, vol. 6, no. 3, (2005), pp. 165-180.

[40] R. Thakur, "Customer adoption of mobile payment services by professionals across two cities in India: An empirical study using modified technology acceptance model [J]", Business Perspectives and Research, vol. 1, (2013), p. 17.

[41] P. M. Podsakoff, S. B. MacKenzie, J. Y. Lee and N. P. Podsakoff, "Common method biases in behavioral research: A critical review of the literature and recommended remedies", Journal of Applied Psychology, vol. 88, no. 5, (2003), pp. 879-903.

[42] H. Liang, N. Saraf and Q. Hu, "Assimilation of enterprise systems: the effect of institutional pressures and the mediating role of top management [J]", MIS quarterly, (2007), pp. 59-87.

[43] P. E. Shrout and N. Bolger, "Mediation in experimental and nonexperimental studies: new procedures and recommendations [J]", Psychological methods, vol. 7, no. 4, (2002), p. 422.

[44] F. Liébana-Cabanillas, F. Muñoz-Leiva and J. Sánchez-Fernández, "The impact of risk on the technological acceptance of mobile payment services [J]", Global Business Perspectives, vol. 1, no. 4, (2013), pp. 309-328.

[45] T. Zhou, "Understanding the determinants of mobile payment continuance usage [J]", Industrial Management \& Data Systems, vol. 114, no. 6, (2014), pp. 6-6.

[46] H. Xin, A. A. Techatassanasoontorn and F. B. Tan, "Exploring the influence of trust on mobile payment adoption [J]", (2013).

[47] E. L. Slade, M. D. Williams and Y. K. Dwivedi, "Mobile payment adoption: Classification and review of the extant literature [J]", The Marketing Review, vol. 13, no. 2, (2013), pp. 167-190.

[48] J. Huang, Y. Li and H. Li, "Study on Factors to Adopt Mobile Payment for Tourism E-Business: Based on Valence Theory and Trust Transfer Theory[M]", Information and Communication Technologies in Tourism 2014. Springer International Publishing, (2013), pp. 747-759.

[49] E. Ho, S. Apostu, F. Michahelles, "Digital Receipts: Fostering Mobile Payment Adoption [M]", Ambient Intelligence. Springer International Publishing, (2013), pp. 140-149.

[50] J. Zhong, A. Dhir, M. Nieminen, "Exploring Consumer Adoption of Mobile Payments in China [C]", MindTrek, (2013), p. 318.

[51] F. Liébana-Cabanillas, J. Sánchez-Fernández and F. Muñoz-Leiva, “Antecedents of the adoption of the new mobile payment systems: The moderating effect of age [J]", Computers in Human Behavior, vol. 35, (2014), pp. 464-478.

[52] D. Straub, M. C. Boudreau and D. Gefen, "Validation guidelines for IS positivist research", Communications of the Association for Information Systems, vol. 13, no. 1, (2004), pp. 380-427.

[53] T. Zhou, "Understanding the effect of flow on user adoption of mobile games", Personal and Ubiquitous Computing, vol. 17, no. 4, (2013), pp. 741-748.

[54] T. Zhou, "An empirical examination of continuance intention of mobile payment services [J]", Decision Support Systems, vol. 54, no. 2, (2013), pp. 1085-1091.

[55] V. Venkatesh, M. G. Morris and G. B. Davis, "User acceptance of information technology: Toward a unified view [J]", MIS quarterly, (2003), pp. 425-478.

[56] H. Y. Wang and S. H. Wang, "User acceptance of mobile internet based on the unified theory of acceptance and use of technology: Investigating the determinants and gender differences [J]", Social Behavior and Personality: an international journal, vol. 38, no. 3, (2010), pp. 415-426.

[57] E. AbuShanab and J. M. Pearson, "Internet banking in Jordan: The unified theory of acceptance and use of technology (UTAUT) perspective [J]", Journal of Systems and Information Technology, vol. 9, no. 1, (2007), pp. 78-97.

[58] S. Laforet and X. Li, "Consumers' attitudes towards online and mobile banking in China [J]", International Journal of Bank Marketing, vol. 23, no. 5, (2005), pp. 362-380. 
[59] T. Zhou, Y. Lu and B. Wang, "Integrating TTF and UTAUT to explain mobile banking user adoption [J]", Computers in Human Behavior, vol. 26, no. 4, (2010), pp. 760-767.

[60] H. F. Lin, "An empirical investigation of mobile banking adoption: the effect of innovation attributes and knowledge-based trust [J]", International Journal of Information Management, vol. 31, no. 3, (2011), pp. 252-260.

\section{Appendix}

Perceived ease of use(EOU) (adapted from Agarwal and Karahanna[27])

EOU1:Learning to use mobile payment is easy for me.

EOU2:Skillfully using mobile payment is easy for me.

EOU3:Overall, mobile payment is easy to use.

Perceived usefulness (PU) (adapted from Agarwal and Karahanna[27])

PU1: Using mobile payment improve my performance in conducting securities transactions.

PU2: Using mobile payment make it easier for me to conduct securities transactions.

PU3: I would find mobile payment useful in conducting my securities transactions.

Structural assurance (SA) (adapted from McKnight et al.[28])

SA1: I feel confident that encryption and other technological advances on the mobile Internet make it safe for me to use mobile payment.

SA2: I feel assured that legal and technological structures adequately protect me from payment problems on the mobile Internet.

SA3: Mobile Internet is a robust and safe environment in which to use mobile banking.

Ubiquity (UB) (adapted from Lee [29])

UB1: I can use mobile banking from anywhere.

UB2: I can use mobile payment at anytime.

UB3: If needed, I can use mobile banking at anytime from anywhere.

Trust (TRUST) (adapted from Lee [29])

TRUST1: Mobile banking is trustworthy.

TRUST2: Mobile banking keeps its promise.

TRUST3: Mobile banking keeps customers' interests in mind.

Usage intention (UI) (adapted from Lee [29])

UI1: Given the chance, I intend to use mobile banking.

UI2: I expect my use of mobile banking to continue in

future.

UI3: I have intention to use mobile banking to conduct payment.

\section{Authors}

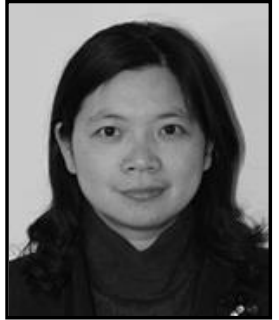

Hong Yan is a Lecturer at School of management, Wuhan University of Science and Technology, Wuhan, China. She received her master degree in Information Science from the School of Information Management, Wuhan University, in 2003. She has published over 10 articles in Chinese journals and in English journals. Her main research interests include individual adoption, technology implementation, customer trust. E-mail: yanhong@wust.edu.cn

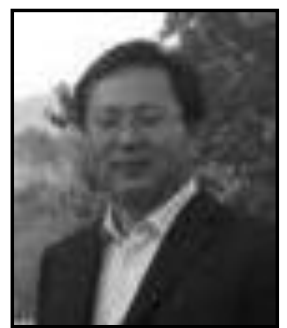

ZhongHua Yang is an associate profess at School of management, Wuhan University of Science and Technology, Wuhan, China. He received his doctoral degree in Management Science from the School of Management, HuaZhong University of Science and technology. He has published over 10 articles. His research interests include supply chain management, individual adoption, technology implementation, and related topics. E-mail: Yzh100@263.net 
International Journal of $u$ - and e- Service, Science and Technology Vol.8, No.1 (2015) 